\title{
Screening for cervical dysplasia in department of genitourinary medicine
}

\author{
I ANNE TAIT, A B ALAWATTEGAMA, ELISABETH REES \\ From the Department of Genitourinary Medicine, University of Liverpool
}

SUMMARY In 632 patients attending a sexually transmitted disease (STD) clinic who were colposcoped because they were in certain high risk groups for cervical neoplasia, and irrespective of cytological findings, 13 out of 51 biopsied had false negative cytology results.

Human papilloma virus (HPV) was the most important sexually transmitted agent associated with cervical intraepithelial neoplasia (CIN), but HPV was also present in most patients with false negative $(11 / 13)$ and false positive (11/14) cytology results. Screening by colposcopy, as well as cervical cytology, is therefore mandatory and must be available for certain STD clinic patients.

In 1842 Rigoni-Stern noted the protective effect of celibacy against cancer of the uterus (not distinguishing it from the cervix), and subsequent epidemiological studies have stressed the probability of a sexually transmitted factor in cervical carcinogenesis. ${ }^{1-3}$ Early age at first intercourse, and multiplicity of partners are important epidemiological features; furthermore, trends in mortality for this cancer closely follow trends in incidence of sexually transmitted disease (STD) ${ }^{4}$ so it is logical preventive medicine to screen women attending STD clinics for cervical dysplasia. ${ }^{5}$

Opportunistic screening by cervical cytology started in this department in 1963, to test women at risk who were unlikely to take advantage of other facilities for cervical cytology. Comments on the failure of the community screening programme in England and Wales suggest that the most women who die of carcinoma of the cervix have never had a smear. ${ }^{6}$

In 1983, using the colposcope and taking biopsy specimens where necessary, we started examining women in certain high risk categories. We found, as others had, a number of younger women who, despite having had a recent negative smear result, had developed advanced cervical malignancy.?

The principal aim of this study was to assess the incidence and degree of cervical dysplasia in these women, using cytology and colposcopy with biopsy,

Address for reprints: Dr I Anne Tait, University Department of Genitourinary Medicine, Royal Liverpool Hospital, Prescott Street, Liverpool L7 8XP

Accepted for publication 31 December 1987 and to note discrepancies between these diagnostic methods. The association of cervical dysplasia and the presence of genital warts was studied, and the relevance of age and oral contraceptive usage was considered.

\section{Patients and methods}

Between March 1985 and August 1986, 632 women attending the department of genitourinary medicine in the Royal Liverpool Hospital were colposcoped for the first time. The indications for colposcopy were $(a)$ vulvar, vaginal, or cervical warts found on clinical examination (390); (b) a history of genital warts in the patient's sexual partner (111); $(c)$ previous genital herpes (microbiologically confirmed) in the patient or her partner (38); (d) persistently abnormal findings in cytology smears taken after the treatment of genital infections (48); (e) cervical abnormalities detected on clinical examination (25); $(f)$ a history of promiscuity or postcoital, intermenstrual, or postmenopausal bleeding (20). (Groups $a, b, c$, e, and $f$ were colposcoped regardless of their cytological status.)

The medical staff had previously obtained the history and carried out the clinical examination. Samples were taken for microbiological screening tests for syphilis and infections with Nesseria gonorrhoeae, Chlamydia trachomatis, Candida spp, Trichomonas vaginalis, other vaginal pathogens, and when indicated, herpes simplex virus. Standard laboratory procedures were used to identify the organisms. ${ }^{8}$ When necessary, appropriate treatment was given and follow up tests carried out.

Women were asked to advise their sexual partners to 
Table 1 Results of colposcopy screening of 632 women

\begin{tabular}{|c|c|c|c|c|}
\hline Indication & No in group & $\begin{array}{l}\text { No biopsied } \\
(n=127)\end{array}$ & $\begin{array}{l}\text { No (\% of group) with } \\
\text { dysplasia on biopsy } \\
(n=51)\end{array}$ & $\begin{array}{l}\text { No showing } \\
\text { at least } \\
\text { CIN III }\end{array}$ \\
\hline $\begin{array}{l}\text { Genital warts } \\
\text { Sexual contact with genital warts } \\
\text { History of genital herpes } \\
\text { Persistent cervical dyskaryosis on cytology } \\
\text { Clinically abnormal cervix } \\
\text { Other high risk factors* }\end{array}$ & $\begin{array}{r}390 \\
111 \\
38 \\
48 \\
25 \\
20\end{array}$ & $\begin{array}{r}80 \\
8 \\
4 \\
26 \\
4 \\
5\end{array}$ & $\begin{array}{rr}28 & (7) \\
1 & (1) \\
1 & (3) \\
20 & (42) \\
1 & (4) \\
0 & \end{array}$ & $\begin{array}{r}12 \\
1 \\
0 \\
8 \\
1 \\
0\end{array}$ \\
\hline
\end{tabular}

CIN III, cervical intraepithelial neoplasia grade 3.

*History of promiscuity or postcoital, intermenstrual, or postmenopausal bleeding.

attend STD clinics for investigation and treatment, and the women were given contact cards.

Cervical cytological smears were taken by the medical staff at the first visit unless this was precluded by obvious inflammation of the lower genital tract or heavy menstrual bleeding. Standard techniques were used employing an Ayre's spatula in a single gentle $360^{\circ}$ sweep. The material obtained was transferred to a slide, which was flooded with fixative. Cytology reporting was carried out by the university department of obstetrics and gynaecology. Varying degrees of dyskaryosis were reported from mild, through moderate, to severe, which roughly correlated with the grades of cervical intraepithelial neoplasia (CIN) from CIN I to III, as recommended by the recent working party of the British Society for Clinical Cytology. ${ }^{9}$ Signs of mild inflammation and wart virus infection were not reported.

All colposcopies were carried out by ABA or IAT using a 120 Zeiss colposcope or OPMI-IFC Zeiss colposcope. Duplication of investigations was avoided by informing the general practitioner briefly (with the patient's permission) of the indication, findings, and further referral, if necessary.

After inspection of the vulva, the cervix was exposed using a bivalve speculum. Any mucus was mopped away, and the cervix, vaginal fornices, and walls were examined both by the naked eye and with the colposcope. When necessary, a repeat smear was taken. Then $5 \%$ acetic acid was lavishly applied to the cervix and vaginal walls. Punch biopsy specimens were taken from any suspect (acetowhite) areas of the cervix if the squamocolumnar junction was visible, using dilating forceps if necessary. Finally, the vaginal fornices and walls were examined, and the speculum was withdrawn. When a biopsy specimen was taken, the woman was asked to return to see the same doctor in three weeks to discuss the results and any further action.

Women were referred to the department of gynaecology for further investigation, and treatment when necessary, if: cervical dysplasia was found in the biopsy specimen; repeat smears showed dyskaryosis despite negative colposcopy or biopsy results (random biopsy specimens were not taken from non-acetowhite areas); in patients with dyskaryosis, colposcopy had been incomplete or unsatisfactory.

\section{Results}

Of 632 women examined by colposcopy in the 16 months from April 1985 to July 1986, 74 had dyskaryotic smears. In 48 of them this dyskaryosis had been the indication for colposcopy, and in the other 26 it was an incidental finding.

Biopsy samples were taken from 127 women because the cervix looked suspect, and $51(40 \%)$ of them showed dysplasia. Table 1 shows the results in the selected groups of patients. (For simplicity, when dyskaryosis or genital warts were present, that indication took precedence over a history of genital herpes or high risk factor in the same woman. No subgroups were employed.) In the 23 women with dysplasia in the absence of genital warts clinically, histological

Table 2 Correlation between results of cytology and histology in 65 women

\begin{tabular}{lcccccc}
\hline & \multicolumn{2}{c}{ Dysplasia on biopsy } & & & \\
\cline { 2 - 7 } Dyskaryosis on cytology & Negative & CIN I & CIN II & CIN III & Cervical cancer & Total \\
\hline Negative & 0 & 4 & 4 & 4 & 1 & 13 \\
Mild (CIN I) & 0 & 0 & 1 & 11 & 0 & 12 \\
Moderate(CIN II) & 13 & 6 & 2 & 0 & 0 & 37 \\
Severe (CIN III) & 1 & 0 & 18 & 22 & 1 & 65 \\
Total & 14 & 10 & & & & \\
\hline
\end{tabular}

CIN, cervical intraepithelial neoplasia. 
evidence of wart virus infection was found in three and of non-specific virus infection in four. Of the 127 women biopsied, 62 with negative smears had negative results. Table 2 shows that, of the remaining 65 women, 38 whose smears had shown dyskaryosis were found to have dysplasia, 13 whose smears had given negative results had dysplasia on biopsy, and 14 with dyskaryotic smears had negative biopsies. (No biopsy specimen had been taken from 22 women with dyskaryotic smears when they were colposcoped). Thus in the 127 women biopsied, the incidence of true positive results on cytology was $75 \%(38 / 51)$, the incidence of true negative results was $82 \%(62 / 76)$, and the incidence of false negative results was $26 \%(13 / 51)$. The overall incidence of false positive results on cytology, including those of women not biopsied, was assumed to be $6 \%(36 / 581)$. Eleven of the 13 women with false negative and 11 of 14 with false positive results had genital warts.

The average age of the 390 women with genital warts was 23 ; in 31 with cervical dysplasia and cervical condylomata the average age was 26 , in 20 with dysplasia but no cervical condylomata it was 28 .

When we examined the use of oral contraceptives in women aged under 25 with warts, $85 \%(11 / 13)$ of women with dysplasia and $65 \%$ (15 23) of those without dysplasia took the pill, not a significant difference.

\section{Discussion}

Research workers in the past decade have produced evidence to suggest that the human papillomavirus (HPV) is the main sexually transmitted infectious agent associated with cervical dysplasia, ${ }^{10-12}$ and up to $30 \%$ of women with vulvar condylomata have been reported as having coexistent cervical dysplasia. ${ }^{13}$ Table 3 shows that the incidence of women with genital warts increased dramatically in 1971-85 in STD clinics both nationally (4-4-fold) (DHSS, unpublished information) and locally (7.3-fold), increases that were greater than the total increases in new women attenders with STD (2.4-fold nationally, and 2.5-fold in this clinic).

Table 3 National and local incidences of all sexually transmitted diseases (STDs) and genital warts in women attending STD clinics

\begin{tabular}{lccr}
\hline & & \multicolumn{2}{c}{ No of cases of: } \\
\cline { 3 - 4 } & Year & All STDs & Warts \\
\hline England and Wales & 1971 & 114711 & 4903 \\
& 1985 & 277346 & 21446 \\
Liverpool & 1971 & 1436 & 54 \\
& 1985 & 3602 & 395 \\
\hline
\end{tabular}

Although cervical dysplasia was found in at least 16 patients with no clinical, colposcopic, or histological evidence of wart virus infection, our figures confirm the importance of genital warts in association with this condition. There are, however, some difficulties in correlating our cytological and histological results, particularly in patients with genital warts. In fact, in a study of 75 unselected new STD clinic patients, Campion and Oriel found 34 with CIN I-III on biopsy, of whom only 13 had abnormal cytology (Campion MJ, unpublished observation).

Cytological assessment has been described as an inexact and subjective science. Meisels and Fortin commented that, because of the limitations of cytological methods, mild dysplasia could not be distinguished from condylomatous lesions on cytological grounds. ${ }^{10}$ Other workers have agreed that assessing wart virus infections may be difficult by cytological, colposcopic, or histological examination alone. ${ }^{14}$ is Similarly, inflammatory cytological changes may be associated with CIN. Toon et al found dysplasia in $12.3 \%$ of women in whom only nonspecific inflammatory changes had been reported. ${ }^{16}$

Mild inflammation was not reported in our patients' cytology results; when inflammation was gross, a repeat smear was requested. Smears had been taken at the first opportunity (with screening tests for genital infection) because compliance of our patients was generally poor. False negative results on cytology may also be due to inadequate cytological sampling. ${ }^{17}$ The technique may be improved by using the Aylesbury spatula and cytobrush when indicated. Cytological reporting is now fuller, and includes notification of wart virus infection and inflammatory changes. Although this is contrary to recent recommendations, it alerts the clinicians and enables them to carry out further investigations and, if necessary, treatment.

The effect of penile condylomata in women's sexual partners as a possible explanation of the "male factor" in cervical cancer, ${ }^{18}$ because condylomata are sexually transmitted, was not obvious. Many women whose indication for attendance at an STD clinic had been their partner's genital warts, were found on clinical examination to have previously unsuspected warts, and that was their indication for colposcopy. This reduced the "warts contacts" to a group of women without any visible warts on clinical examination.

Herpes simplex virus (HSV) is no longer considered of prime importance in cervical neoplasia, ${ }^{19}$ and that was illustrated here. Zur Hausen has suggested that HSV is a mutagen in HPV infected tissue already predisposed to neoplastic change. ${ }^{20}$ The prevalence of unrecognised cervical HSV infection without vulvar lesions is not known, and such infection may have accompanied HPV in some patients. 
Syrjänen et al have said that cervical dysplasia appears in younger women when associated with condylomata. ${ }^{21}$ In our STD clinic population, which was much younger on average than the gynaecological patients usually examined, we found this is to be so. Women with dysplasia but without warts had a higher mean age than those with dysplasia and warts.

We did not find a significant relation between the use of oral contraception and cervical dysplasia, but in patients aged under 25 who had warts a greater proportion with dysplasia than without dysplasia used the pill. With larger numbers of patients, and by excluding those who used barrier contraception, our findings might have agreed statistically with those of Vessey et al, who observed an increased incidence of neoplasia associated with long term use of oral contraception. ${ }^{22}$ The hormonal content of the pill has, however, been reduced since the period (1968-74) of that study.

The sexual activity of many women STD clinic patients puts them at risk of cervical neoplasia, and this risk is increased when they have genital warts. It is therefore important to bear in mind that cytology results are unreliable if cervical HPV infection is present, and that cervical inflammation caused by other genital tract infections may also make cytological interpretation difficult.

Thus cytological screening in STD clinics must be backed up by colposcopy of high risk groups. Such facilities should be available in all health regions, at least in the larger STD clinics. ${ }^{23}$ The patients and their partners, their varying susceptibility, cofactors, and the progress of dysplasia may be investigated using a combination of cytology, colposcopy, and biopsy, so that treatment may be given when appropriate.

In these investigations, and for the further treatment of many patients, we will continue to co-operate closely with our gynaecological colleagues, from whose expertise many of us have learned. The mutual exchange of junior staff between our two departments would particularly benefit training in both disciplines.

We are indebted to Dr A S Woodcock, lecturer in gynaecological pathology, for advice in the preparation of this paper, and to Mr P J Nickson, chief Medical Laboratory Scientific Officer in the department of obstetrics and gynaecology of the University of Liverpool, for help with the tables.

\section{References}

1 Gagnon F. Contributions to the study of the etiology and prevention of cancer of the cervix of the uterus. Am J Obstet Gynecol 1950;60:516-22.
2 Rotkin ID. Adolescent coitus and cervical cancer: associations of related events with increased risk. Cancer Res 1967;27:603-17.

3 Harris RWC, Brinton LA, Cowdell RH, et al. Characteristics of women with dysplasia or carcinoma in situ of the cervix uteri. Br J Cancer 1980;42:359-69.

4 Beral V. Cancer of the cervix: a sexually transmitted infection? Lancet 1974; i: 1037-40.

5 Anonymous. Genital cancer. In: Tindall VR, ed. Jeffcoate's principles of gynaecology. 5th ed. London: Butterworth, 1987: 488.

6 Chamberlain J. Failures of the cervical cytology screening programme. Br Med J 1984;289:853-4.

7 Chisholm DK, Haran D. Cases of invasive cervical cancer in the North West in spite of screening. British Journal of Family Planning 1984;10:3-8.

8 Davies JA, Rees E, Hobson D, Karayiannis P. Isolation of Chlamydia trachomatis from Bartholin's ducts. British Journal of Venereal Diseases 1978;54:409-13.

9 Evans DMD, Hudson EA, Brown CL, et al. Terminology in gynaecological cytopathology: report of the working party of the British Society for Clinical Cytology. J Clin Pathol 1986;39:933-44.

10 Meisels A, Fortin R. Condylomatous lesions of the cervix and vagina. 1. Cytologic patterns. Acta Cytol 1976;20:505-9.

11 Purola E, Savia E. Cytology of gynecologic condyloma acuminatum. Acta Cytol 1977;21:26-31.

12 Syrjänen K, Väyrynen M, Saarikoski S, et al. Natural history of cervical history of cervical human papilloma virus (HPV) infections based on prospective follow-up. Br J Obstet Gynaecol 1985;92:1086-92.

13 Walker PG, Colley NV, Grubb C, Tejerina A, Oriel JD. Abnormalities of the uterine cervix in women with vulvar warts. British Journal of Venereal Diseases 1983;59:120-3.

14 Kirkup W, Evans AS, Brough AK, et al. Cervical intraepithelial neoplasia and "warty" atypia: a study of colposcopic, histological and cytological characteristics. $\mathrm{Br} J$ Obstet Gynaecol 1982;89:571-7.

15 Walker PG, Singer A, Dyson JL, Shah KV, Wilters J, Coleman DV. Colposcopy in the diagnosis of papillomavirus infection of the uterine cervix. Br J Obstet Gynaecol 1983;90:1082-6.

16 Toon PG, Arrand JR, Wilson LP, Sharp DS. Human papillomavirus infection of the uterine cervix of women without cytological signs of neoplasia. Br Med J 1986;293:1261-4.

17 Husain OAN. Diagnostic errors in cytology. In: Jordan JA, Sharp F, Singer A, eds. Preclinical neoplasia of the cervix. London: Royal College of Obstetricians and Gynaecologists, 1982:111-32.

18 Singer A, Reid BL, Coppleson M. A hypothesis: the role of a highrisk male in the etiology of cervical carcinoma. Am J Obstet Gynecol 1976;126:110-5.

19 Vonka V, Kanka J, Hirsch I, et al. Prospective study on the relationship between cervical neoplasia and herpes simplex type- 2 virus. II. Herpes simplex type-2 antibody presence in sera taken at enrolment. Int $J$ Cancer 1984;33:61-6.

20 zur Hausen $H$. Human genital cancer: synergism between two virus infections or synergism between a virus infection and initiating events? Lancet 1982;ii:1370-2.

21 Syrjänen KJ, Heinonen U-M, Kauraniemi T. Cytologic evidence of the association of condylomatous lesions with dysplastic and neoplastic changes in the uterine cervix. Acta Cytol 1981;25: 17-22.

22 Vessey MP, Lawless M, McPherson K, Yates D. Neoplasia of the cervix uteri and contraception: a possible adverse effect of the pill. Lancet 1983;ii:930-4.

23 Hicks DA, Bushell TEC. Colposcopy in genituourinary medicine clinics. Genitourin Med 1986;62:284. 